\title{
Isolated epiglottic tuberculosis: presented as severe respiratory distress
}

\author{
Saurabh Gupta ${ }^{1 *}$, Ashok Kumar Singh², Anjali Tiwari ${ }^{3}$
}

\author{
${ }^{1}$ Department of ENT, ${ }^{2}$ Department of Pulmonology, ${ }^{3}$ Department of Pathology, Regency Hospital, Kanpur, Uttar \\ Pradesh, India
}

Received: 16 April 2020

Revised: 07 June 2020

Accepted: 09 June 2020

\author{
*Correspondence: \\ Dr. Saurabh Gupta, \\ E-mail: dr.saurab@gmail.com
}

Copyright: (c) the author(s), publisher and licensee Medip Academy. This is an open-access article distributed under the terms of the Creative Commons Attribution Non-Commercial License, which permits unrestricted non-commercial use, distribution, and reproduction in any medium, provided the original work is properly cited.

\begin{abstract}
Tuberculosis is a systemic disease and it can involve any organ of the body. Laryngeal tuberculosis, caused by mycobacterium tuberculosis is quite common in our ENT practice but it is usually a complication of pulmonary tuberculosis, and most patients with laryngeal tuberculosis have coexisting active pulmonary tuberculosis. Most of the times the area of involvement in this secondary laryngeal tuberculosis is posterior part of the larynx. We are reporting a case of isolated primary epiglottic tuberculosis, which is a rare entity, who presented with severe respiratory distress and inspiratory stridor. It was initially suspected and misdiagnosed as a case of laryngeal carcinoma because of common laryngoscopic findings of diffuse edema, deformed laryngeal cartilages and ulcerations in both of these conditions but on further evaluation it was diagnosed as primary epiglottic tuberculosis with no pulmonary involvement. After making the correct diagnosis from histopathological examination, the patient was managed successfully by anti tubercular treatment.
\end{abstract}

Keywords: Acute respiratory distress, Epiglottic tuberculosis, Laryngeal carcinoma

\section{INTRODUCTION}

Primary laryngeal tuberculosis is a rare form of extra pulmonary tuberculosis. ${ }^{1}$ It commonly involves the vocal folds and the ventricular bands. Primary Isolated epiglottic tuberculosis is very rare. Incidence of laryngeal tuberculosis is now less than $1 \%$ of all tuberculosis cases. $^{2}$ At present, more than half of laryngeal tuberculosis cases are due to hematogenous seeding. ${ }^{3}$ Due to its vague clinical presentation and because of a lack of clinical suspicion, laryngeal tuberculosis is frequently confused with laryngeal carcinoma. ${ }^{3}$ Its clinical features include odynophagia, cough, and hoarseness of voice. ${ }^{4}$ It is highly contagious and hence its early diagnosis is very important. ${ }^{5}$ Most of the patients with laryngeal TB have active pulmonary tuberculosis, the sputum-positive rate being $90-95 \% .^{6}$

\section{CASE REPORT}

A 66 year old man presented in emergency department with complaint of hoarseness of voice, stridor and severe respiratory distress from last 2 days. Symptoms severity was more in supine posture. He was also having dysphagia, odynophagia and loud snoring from last one week. All symptoms were progressive. Patient was diabetic, hypertensive, chronic smoker and a case of chronic obstructive pulmonary disease with obstructive sleep apnea (OSA). He was on regular bilevel positive airway pressure therapy. On examination (respiratory rate was 28 per minutes, $\mathrm{Spo}_{2}$ was $88 \%$ and his blood presure was $150 / 70 \mathrm{mmHg}$. Rest of the systemic examination and biochemical tests were normal. His high-resolution computed tomography thorax and 2D echo-cardiography was normal. Sputum examination was negative for acid fast bacilli. Fibreoptic laryngoscopy revealed a growth like lesion in upper part of epiglottis with ulcerated 
mucosa. The true vocal cords were mobile and normal (Figure $1 \mathrm{~A}$ and $\mathrm{B}$ ).
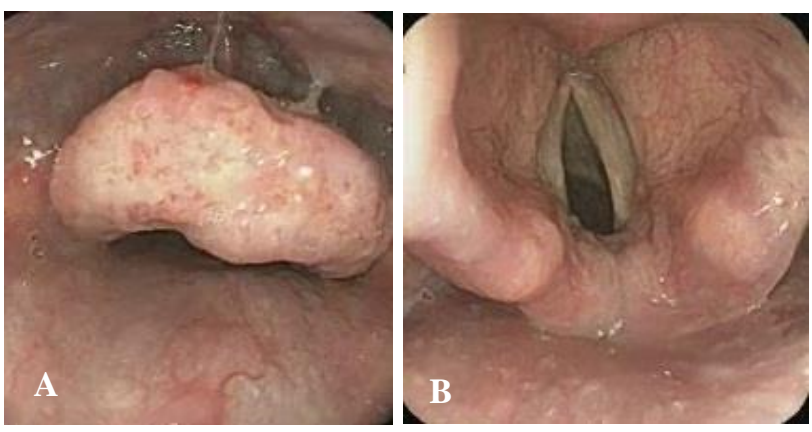

Figure 1 (A and B): Enlarged epiglottis with irregular mucosal surface and normal vocal cords.

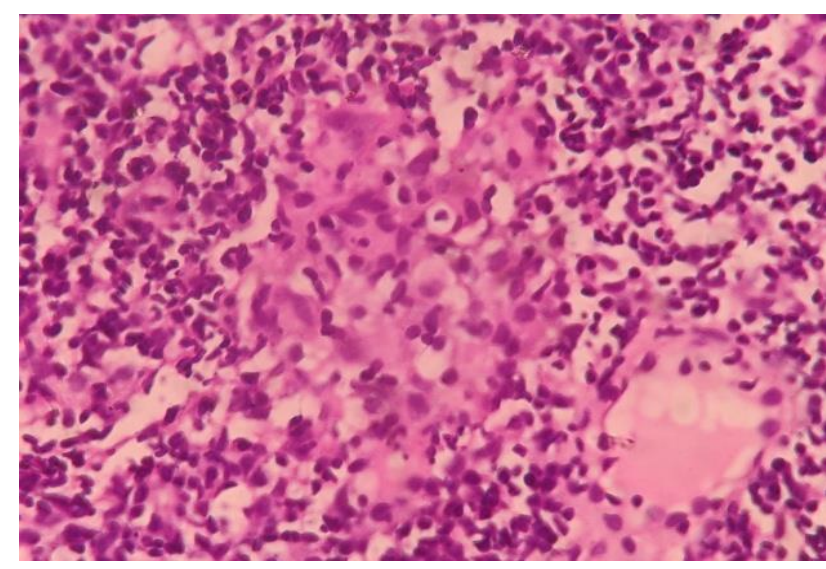

Figure 2: Biopsy specimen showing epithelioid granulomas with caseation necrosis.

It was initially thought to be malignant growth of the epiglottis. Direct laryngoscopy under LA revealed a friable and ulcerated growth in epiglottis. Multiple biopsies were taken. Histopathological examination revealed well-formed epithelioid granulomas with evidence of small area of caseation necrosis, suggestive of tubercular granulomas (Figure 2). Gene xpert was positive for Mycobacterium tuberculosis and was sensitive to rifampicin. Patient was further evaluated for any evidence of active tuberculosis in lung and any other organ of the body but there was no evidence of healed or active tuberculosis. He was advised antitubercular therapy and other supportive measure. Patient responded well to anti tubercular treatment.

Very few cases of isolated epiglottic tuberculosis have been reported. This case is unique in the respect that tuberculosis can affect any part of human body in isolation and can present with atypical clinical presentation.

\section{DISCUSSION}

Tuberculosis is a systemic disease and it can involve any organ of the body. Laryngeal tuberculosis, caused by
Mycobacterium tuberculosis is usually a complication of pulmonary tuberculosis, and most patients with laryngeal tuberculosis have coexisting active pulmonary tuberculosis. Isolated epiglottic tuberculosis has rarely been described. Particularly, in the last two decades, reports of epiglottic tuberculosis have increased. ${ }^{7}$ Laryngeal tuberculosis and carcinoma share similar clinical findings, such as, hoarseness, odynophagia, cough, stridor, hemoptysis and cervical lymphadenopathy. Laryngoscopic findings of diffuse edema and inflammation, a mass, obliteration of anatomic landmarks and ulcerative lesions of epiglottis are other similarities between malignancy and tuberculosis. ${ }^{8}$ Differential diagnosis includes systemic diseases such as Wegener granulomatosis, sarcoidosis, fungal infections and syphilis. ${ }^{9}$ Laryngeal tuberculosis and squamous cell carcinoma can coexist in the same patient and laryngoscopic findings are often indistinguishable. ${ }^{10}$ In this clinical scenario the correct diagnosis of laryngeal carcinoma can only be made by microbiology and biopsy. The clinical presentation in our case is indicates that disease was confined to epiglottis because there was no signs or symptoms of tubercular toxemia. Also, there was no involvement of cervical lymph nodes.

\section{CONCLUSION}

Mycobacterium tuberculosis can affect any part of body. Since laryngeal tuberculosis is generally associated with active pulmonary disease and no pulmonary involvement was demonstrated in our case, it was diagnosed as primary tuberculosis of the epiglottis in an immunocompetent patient. Its presentation may be atypical, like in our case, patient presented with OSA and inspiratory stridor. However, to establish a definitive diagnosis, tissue diagnosis, chest radiographs, and microbiological investigations are necessary.

Funding: No funding sources

Conflict of interest: None declared

Ethical approval: Not required

\section{REFERENCES}

1. Uslu C, Oysu C, Uklumen B. Tuberculosis of the epiglottis: A case report. Eur Arch Otorhinolaryngol. 2008;265:599-601.

2. Williams RG, Tony DJ. Mycobacterium marches back. J Laryngol Otol. 1995;109:5-13.

3. Lin CJ, Kang BH, Wang HW. Laryngeal tuberculosis masquerading as carcinoma. Eur Arch Otorhinolaryngol. 2002;259:521-3.

4. Richter B, Fradis M, Köhler G, Ridder GJ. Epiglottic tuberculosis: differential diagnosis and treatment.Case report and review of the literature. Ann Otol Rhinol Laryngol. 2001;110:197-201.

5. Diktaban T, Lucente FE. Laryngeal tuberculosis: A hazard to the Otolaryngologist. Ear Nose Throat J. 1980;59:488-94. 
6. Soda A, Rubio H, Salazar M, Ganem J, Berlanga D, Sanchez A. Tuberculosis of the larynx: Clinical aspects in 19 patients. Laryngoscope. 1989;99:114750.

7. Edizer DT, Karaman E, Mercan H, Alimoglu Y, Esen T, Cansiz H. Primary tuberculosis involving epiglottis: A rare case report. Dysphagia. 2010;25:258-60.

8. Munck K, Mandpe AH. Mycobacterial infections of the head and neck. Otolaryngol Clin North Am. 2003;36(4):569-76.

9. Yencha MW, Linfesty R, Blackmon A. Laryngeal tuberculosis. Am J Otolaryngol. 2000;21(2):122-6.
10. Singh B, Balwally AN, Nash M, Har-El G, Lucente FE. Laryngeal tuberculosis in HIV-infected patients: a difficult diagnosis. Laryngoscope. 1996;106(10):1238-40.

Cite this article as: Gupta S, Singh AK, Tiwari A. Isolated epiglottic tuberculosis: presented as severe respiratory distress. Int J Otorhinolaryngol Head Neck Surg 2020;6:1364-6. 